\title{
Active quinine-based films able to release antimicrobial compounds via melt quaternization at low temperature ${ }^{\dagger}$
}

\author{
Alejandro Latorre-Sánchez, ${ }^{\mathrm{ab}}$ Mats Johansson, ${ }^{\mathrm{c} *}$ Yuning Zhang, ${ }^{\mathrm{c}}$ Michael Malkoch, ${ }^{\mathrm{c}}$ and José A. \\ Pomposo $^{\mathrm{abd} *}$
}

\begin{abstract}
Fabrication of antibacterial films based on renewable materials (e.g., chitosan) has attracted significant interest for the food-packaging, health and medical fields. However, exploiting the antibacterial properties of cinchona alkaloids to design active nanostructured films able to release quinine-based antimicrobial compounds has not been considered previously. Herein, we develop two different routes to produce active quinine-based nanostructured cross-linked films by exploiting the multiple reactive sites of quinine and, specifically, both the nitrogen atom and the vinyl group of the quinuclidine portion of the molecule, as well as their corresponding orthogonal quaternization and thiol-ene coupling reactions. The first synthetic strategy gives to stiff and brittle nanostructured quinine-based films of limited utility for practical applications. Conversely, the second approach gives to active, flexible and nanostructured quinine-based films $\left(T_{\mathrm{g}}=-14^{\circ} \mathrm{C}\right.$ Young's modulus $=1.3 \mathrm{GPa}$ ) which are able to release antimicrobial compounds against $E$. coli that, remarkably, are noncytotoxic against mouse macrophage and human dermal fibroblast cells. These kind of active cinchona alkaloid-based coatings are easy to prepare by means of simple, solvent-free, melt quaternization / spreading procedures at relatively low temperature $\left(120^{\circ} \mathrm{C}\right)$ making this second approach one of the most facile reported procedures to date to produce active nanostructured bio-based films.
\end{abstract}

\section{Introduction}

Replacement of inert synthetic films by active bio-based coatings offers many opportunities to develop innovative products for the food-packaging, health and medical fields. Avoiding bacterial biofilm infections is one of the most active aims in the design of modern medical devices and prostheses such as artificial heart valves, ${ }^{1}$ intravenous catheters, ${ }^{2}$ hip prostheses, ${ }^{3}$ and dental implants. ${ }^{4}$ Also antibacterial fabric bandages have been developed based on the use of benzalkonium chloride in the wound pad, or silver nanoparticles to prevent infections. ${ }^{5}$ Two mechanisms can provide antibacterial protection: i) passive protection in which the own surface avoids protein adsorption and fouling processes (e.g., by using self-assembled monolayers ${ }^{6}$ to modify the surface energy or by growing poly(ethylene glycol) (PEG) brushes $^{7}$ to give PEGylated surfaces that resist the attachment of bacteria) and ii) active protection in which often an antibacterial compound is progressively released from the coating. ${ }^{8}$ In the latter case, a stringent requirement for the antibacterial compound is to demonstrate noncytotoxic activity during use.

Quinine, 1, (see Fig. 1) is a natural compound extracted from the bark of cinchona and remijia trees, which for centuries constituted the only effective remedy to malaria. ${ }^{9}$ This cinchona alkaloid has been recognized as "the drug to have relieved more human suffering than any other in history" ${ }^{10}$ In addition to the use of quinine as a treatment of systemic lupus erythematosus and rheumatoid arthritis, quinine salts have also been investigated as an effective treatment against Herpes simplex virus, ${ }^{11}$ and different Grampositive and Gram-negative pathogenic organisms. ${ }^{12}$ Remarkably, quinine sulfate was reported to inhibit invasion of some bacterial skin pathogens. ${ }^{13}$ Moreover, significant antibacterial activity of amphiphilic cationic quinine-derived compounds against most pathogenic bacteria, including methicillin-resistant $S$. aureus, has been reported. ${ }^{14}$

Despite the large number of proposed passive and active coatings based on renewable materials (e.g., chitosan), ${ }^{15}$ exploiting the antibacterial properties of cinchona alkaloids to design active nanostructured antibacterial films has not been considered previously. Herein we introduce, for the first time, a versatile and solvent-free synthetic strategy toward active nanostructured cinchona alkaloid-based coatings by means of simple melt quaternization / spreading procedures at relatively low temperature $\left(120^{\circ} \mathrm{C}\right)$. By combining this ground-breaking concept with the multiple reactive sites of $\mathbf{1}$ and, specifically, both the nitrogen atom and the vinyl group of the quinuclidine portion of the molecule, as well as their corresponding orthogonal quaternization ${ }^{16}$ and thiol-ene coupling ${ }^{17}$ reactions, we produce a unique type of active nanostructured quininebased cross-linked films that are able to release quinine-based 


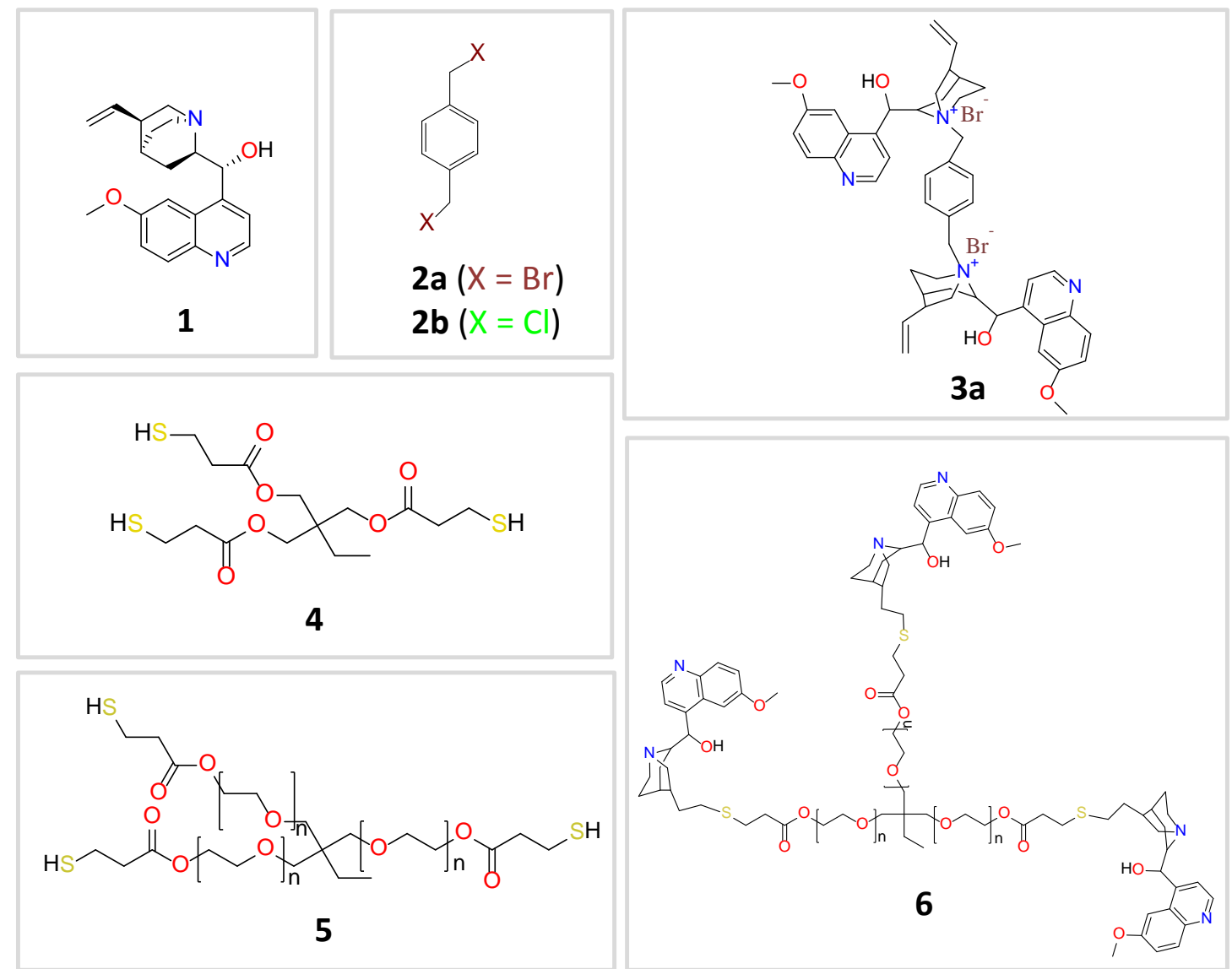

Fig. 1 Chemical compounds utilised in this work to design active nanostructured cinchona alkaloid-based coatings.

antimicrobial compounds that, remarkably, are noncytotoxic against mouse macrophage and human dermal fibroblast cells.

\section{Results and discussion}

The different precursors of the quinine-based films investigated in this work are illustrated in Fig. 1, whereas their source / synthetic details are reported in the Electronic Supplementary Information, ESI. Two different routes to produce quinine-based films were investigated. When crosslinking of compounds $\mathbf{3}$ and $\mathbf{4}$ (Fig. 1) was performed in DMSO solution through UV-activated thiol-ene coupling, stiff and brittle quinine-based films of limited utility for practical applications were the result. On the contrary, when crosslinking of precursors 2 and 6 (Fig. 1) was carried out via melt quarternization, unique active nanostructured quinine-based cross-linked films able to release antimicrobial compounds against $E$. coli were obtained showing, remarkably, noncytotoxic activity against mouse macrophage and human dermal fibroblast cells. The first synthetic strategy followed to produce quinine-based films involved the synthesis of compound 3 ( $3 a, X=B r ; 3 b, X=C l$ ) from 1 and 2 via quaternization. The reaction was carried out in DMSO at $80^{\circ} \mathrm{C}$ for $24 \mathrm{~h}$ and 3 was isolated by simple precipitation in tetrahydrofuran and further drying under dynamic vacuum (yield $=58 \%$, 3a; $65 \%, 3 \mathbf{b}$ ). The ${ }^{1} \mathrm{H}$ NMR spectrum of $\mathbf{3 a}$ is shown in Figure $2 \mathrm{~A}$. Assignment of peaks was assisted by ${ }^{1} \mathrm{H}$ COSY and ${ }^{1} \mathrm{H}^{13}{ }^{13} \mathrm{C}$ HSQC NMR measurements (see ESI). Elemental analysis results of $\mathbf{3} \mathbf{a}$ and $\mathbf{3} \mathbf{b}$ were found in excellent agreement with the expected chemical composition of each compound. Figure 2B shows the MALDI-TOF spectra of 3a and 3b. In both cases two peaks were observed corresponding to molecules that have lost at least one $(3 \mathbf{a}-1 \mathrm{Br}, \mathbf{3 b}-1 \mathrm{Cl})$ or two $(3 \mathbf{a}-2 \mathrm{Br}, \mathbf{3} \mathbf{b}-\mathbf{2} \mathrm{Cl})$ counter-ion halogen atoms during the laser desorption/ionization experiments. Overall, all the characterization techniques support the synthesis of $\mathbf{3 a}$ and $\mathbf{3 b}$ in good yield with excellent purity. In a next step, $\mathbf{3}$ was reacted with the trifunctional thiolated cross-linker 4 (Fig. 1) in DMSO via UV-activated thiol-ene coupling reaction for $1.5 \mathrm{~h}$ to give -upon solvent removal at $120{ }^{\circ} \mathrm{C}$ overnight- a quininebased cross-linked film denoted as $\mathbf{F} 1$ (F1a, $X=\mathrm{Br}$; F1b, $\mathrm{X}=\mathrm{Cl}$ ) 


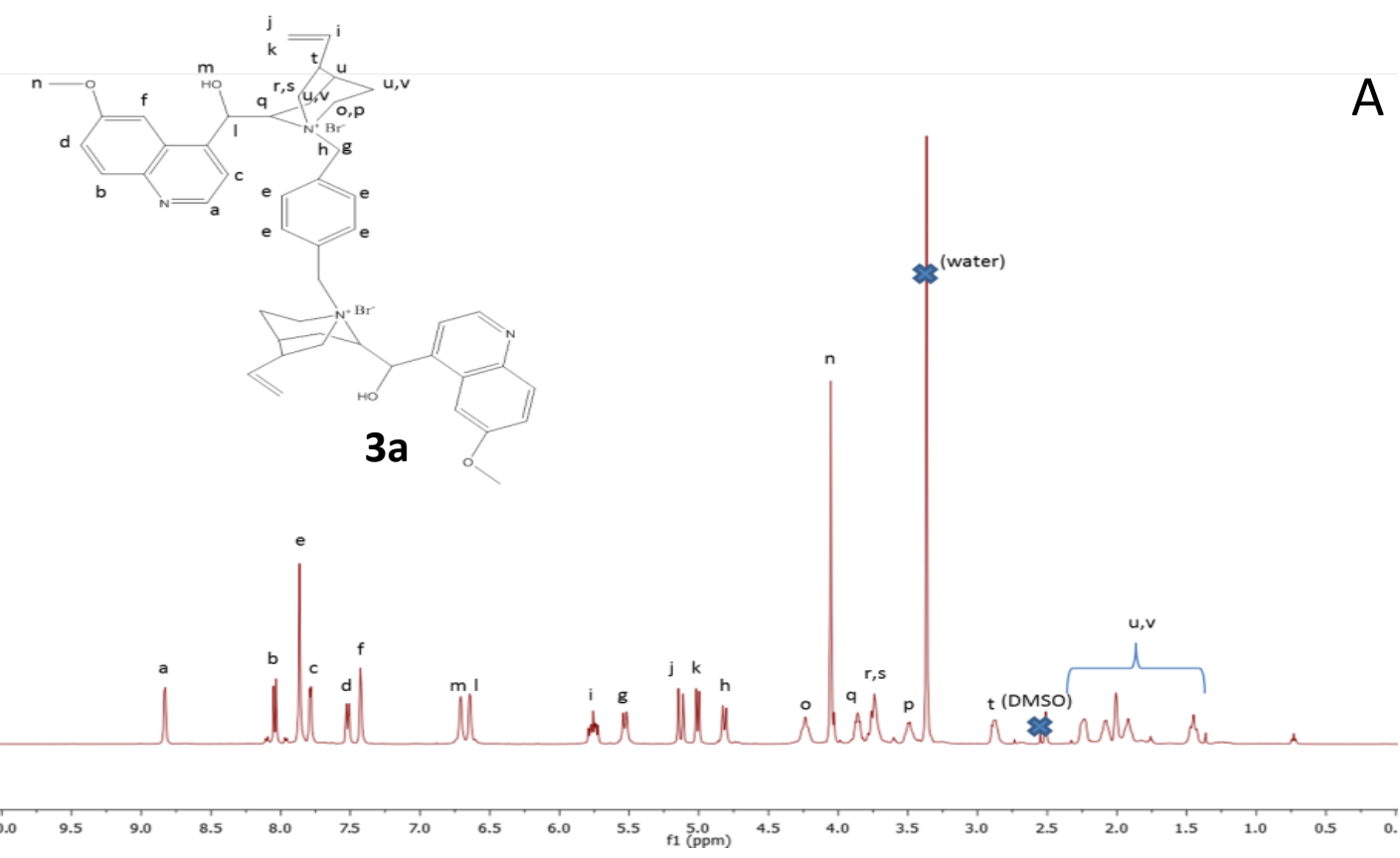

A
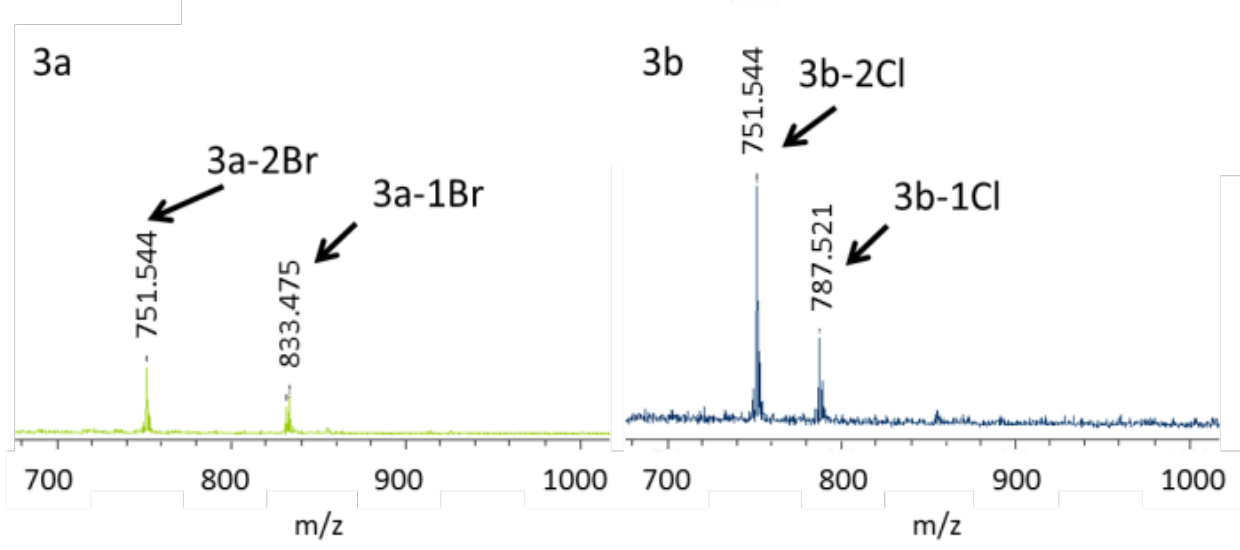

Fig. 2 A) ${ }^{1}$ H NMR spectrum of $\mathbf{3 a}$ (for assignment of peaks see ESI). B) MALDI-TOF spectra of $\mathbf{3 a}$ and $\mathbf{3 b}$ (see text).

(Fig. 3A). The partial consumption of vinyl groups of $\mathbf{3 a}$ by reaction with thiol groups of $\mathbf{4}$ was confirmed by attenuated total reflectance Fourier transform infra-red (ATR-FTIR) spectroscopy through the decrease in the intensity of the bands associated to the stretching and bending vibrations of the $\mathrm{C}=\mathrm{C}$ bond (ca. $1600 \mathrm{~cm}^{-1}$ and $c a .830 \mathrm{~cm}^{-1}$, respectively) (see ESI). The incorporation of 4 to the cross-linked, insoluble films was confirmed by the appearance of a new band at $c a$. $1735 \mathrm{~cm}^{-1}$ associated to the stretching vibration of $\mathrm{C}=\mathrm{O}$ groups, when compared to the FTIR spectrum of neat 3a. Nanoscale characterization of the films was carried out by peak force quantitative nanomechanical mapping (PF-QNM) measurements (Fig. 3B). The roughness of the bromide quaternized film F1a, as determined from topography maps, was found to be slightly higher than the roughness of the chloride quaternized film F1b but both were on average below 2-3 nm, showing a relatively flat surface at nanoscale level. Mechanical modulus PF-QNM pictures revealed the nanostructured nature of the films as illustrated in Fig. 3B. In both cases, a narrow distribution of Young's modulus centered between 4 and $6 \mathrm{GPa}$ was observed by PF-QNM (Fig. 3C), which is comparable to the Young's modulus of biocompatible polymers such as poly(lactic acid) and poly(glycolide).$^{18}$ Nevertheless, films F1a and F1b were found to be very brittle 


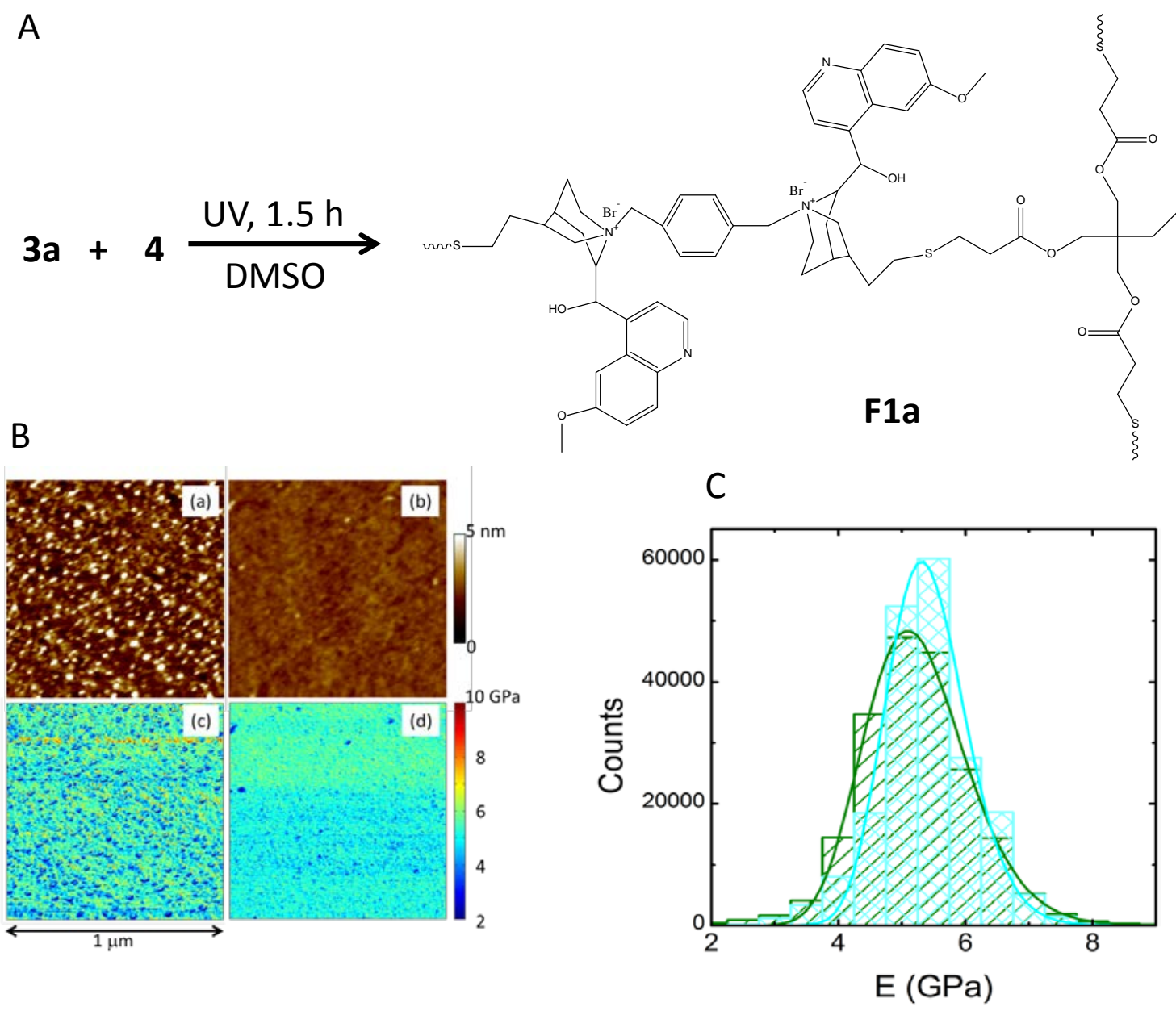

Fig. 3 A) Synthesis of quinine-based film F1a by reaction of $\mathbf{3 a}(\mathrm{X}=\mathrm{Br})$ and $\mathbf{4}$ via UV-activated thiol-ene coupling reaction with further solvent removal. B) Topography and Young's modulus pictures of films F1a ((a) and (c), respectively) and F1b ((b) and (d), respectively) as determined by peak force quantitative nanomechanical mapping (PF-QNM) experiments. C) Young's modulus distribution corresponding to film F1a (dark green) and F1b (light blue).

and hence of limited utility for practical applications.

To increase film flexibility without involving high boiling point solvents, we turned our attention to a commercially available trifunctional thiolated cross-linker having short PEG segments in its chemical structure, 5 (Fig. 1). Compound 5 is amorphous at room temperature, without any sign of crystallinity and with a glass transition temperature $\left(T_{\mathrm{g}}\right)$ of -60 ${ }^{\circ} \mathrm{C}(\mathrm{ESI})$. We reasoned that incorporation of 5 to quinine-based films could improve the resulting film flexibility upon crosslinking. Moreover, above room temperature, the viscosity of $\mathbf{5}$ is such that it can be manipulated as a liquid without involving external solvents. Consequently, we synthesized compound 6 (Figure 4A) from 1 and 5 via UV-activated thiol-ene coupling reaction to be used as quinine-containing cross-linker during the subsequent step of film formation via quaternization with 2b. The synthesis of $\mathbf{6}$ was carried out in DMSO at room temperature under UV irradiation for $3 \mathrm{~h} . \mathbf{6}$ was isolated in 20 $\%$ yield by simple precipitation in toluene and further drying under dynamic vacuum. The ${ }^{1} \mathrm{H}$ NMR spectrum of $\mathbf{6}$ is shown in Figure 4B. Assignment of peaks was assisted by ${ }^{1} \mathrm{H}_{-}{ }^{13} \mathrm{C}$ HSQC and ${ }^{1} \mathrm{H}$ COSY NMR measurements performed to neat 5 and 6 (Figure 4C). Confirmation of the successful formation of $\mathbf{6}$ was also gained by ATR-FTIR spectroscopy (see ESI). When compared to neat 5, compound 6 showed a value of $T_{\mathrm{g}}$ of -18 ${ }^{\circ} \mathrm{C}$ with no signs of crystallization. Consequently, incorporation of quinine moieties to $\mathbf{5}$, even if increasing the value of $T_{\mathrm{g}}$, still produces an amorphous compound which could improve the flexibility of the resulting cross-linked films. Thermogravimetric analysis measurements showed that 6 had no weight loss until $180^{\circ} \mathrm{C}$ (see ESI). 6 was, to our delight, an excellent precursor of 


\section{$\mathrm{A} \quad 1+5 \underset{\mathrm{DMSO}}{\stackrel{\mathrm{UV}, 3 \mathrm{~h}}{\longrightarrow}} 6$}

B
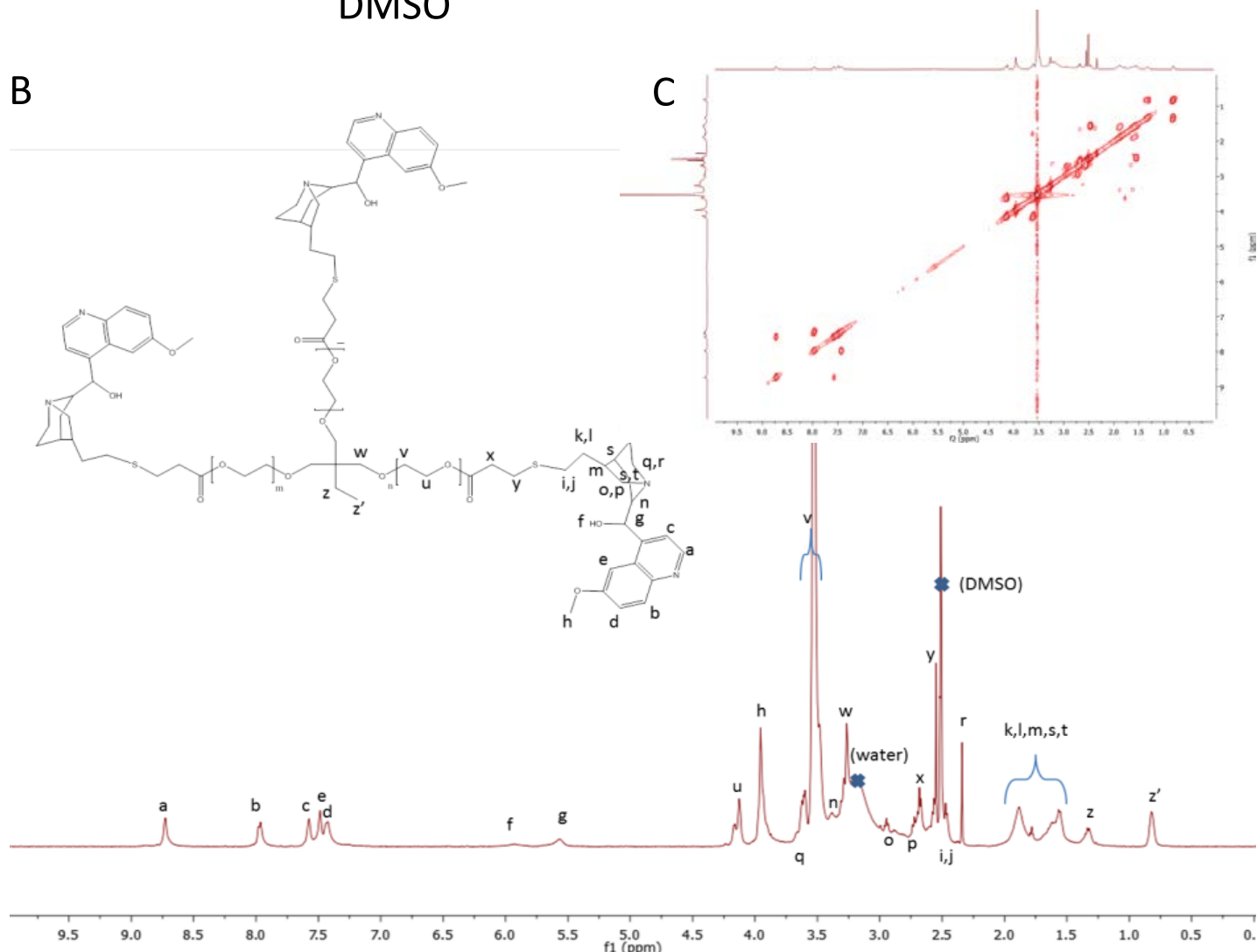

Fig. 4 A) Illustration of reaction conditions employed to synthetize 6 from 1 and 5 via UV-activated thiol-ene coupling reaction. B) ${ }^{1} \mathrm{H}$ NMR spectrum of 6 . C) ${ }^{1} \mathrm{H}$ COSY spectrum of 6 .

valuable, active quinine-based film F2b $(X=C l)$ when quaternized in the melt with $\mathbf{2} \mathbf{b}$ which has a melting point of ca. $100{ }^{\circ} \mathrm{C}$. Film formation involved the mixing of $\mathbf{2 b}$ and $\mathbf{6}$ at $120{ }^{\circ} \mathrm{C}$, followed by spreading the resulting blend on a thin glass that is maintained at such temperature for $48 \mathrm{~h}$ (see Figure $5 \mathrm{~A}$ and $\mathrm{ESI}$ ). The cross-linking degree of $\mathbf{F 2} \mathbf{b}$ was easily tuned by changing the [2b] / [quinine] ratio (see ESI). In all cases investigated ([2b] / [quinine] ratio $=1 / 8$ (denoted as film F2b-A), 1/4 (film F2b-B), 1/3 (film F2b-C) and 1/2 (film F2b-D)), flexible cross-linked films resulted that were not soluble in DMSO, water or any other organic solvent. The insolubility of the films precluded their characterization by NMR techniques in solution. ATR-FTIR spectroscopy was used to monitor the changes in the vibration bands upon film formation, when compared to neat 6 . Unfortunately, due to the presence of multiple, overlapping IR bands it was not possible to assign specific quaternization vibration bands. Film F2b-D showed a value of $T_{\mathrm{g}}$ of $-14{ }^{\circ} \mathrm{C}$ with no signs of crystallinity. Nanoscale characterization of the quinine-based films was carried out by PF-QNM measurements and compared to that of compound 6 (Figure 5B). The roughness of the melt quaternized film $D$ was found to be slightly higher than that shown by a soluble film of neat compound $\mathbf{6}$ although both films showed a relatively flat surface at nanoscale level (roughness $<2-3 \mathrm{~nm}$ ). The nanostructured nature of film $\mathbf{D}$ can be clearly appreciated in Fig. 5B. The melt quaternized film $\mathbf{D}$ showed an average value of Young's modulus of $1.3 \mathrm{GPa}$, slightly higher than that corresponding to the film of compound $6(1.1 \mathrm{GPa})$ due to its network, cross-linked structure. A significant reduction in the Young's modulus of film $\mathbf{D}$ was observed when compared to films F1a and F1b obtained by cross-linking in DMSO solution through UV-activated thiol-ene coupling. In fact, the value of Young's modulus of film D was similar to that found for polymers like poly(quinoline) and poly(p-xylylene), as well as biological materials like bacteriophage capsids. ${ }^{19}$

One of the main advantages of the second strategy 


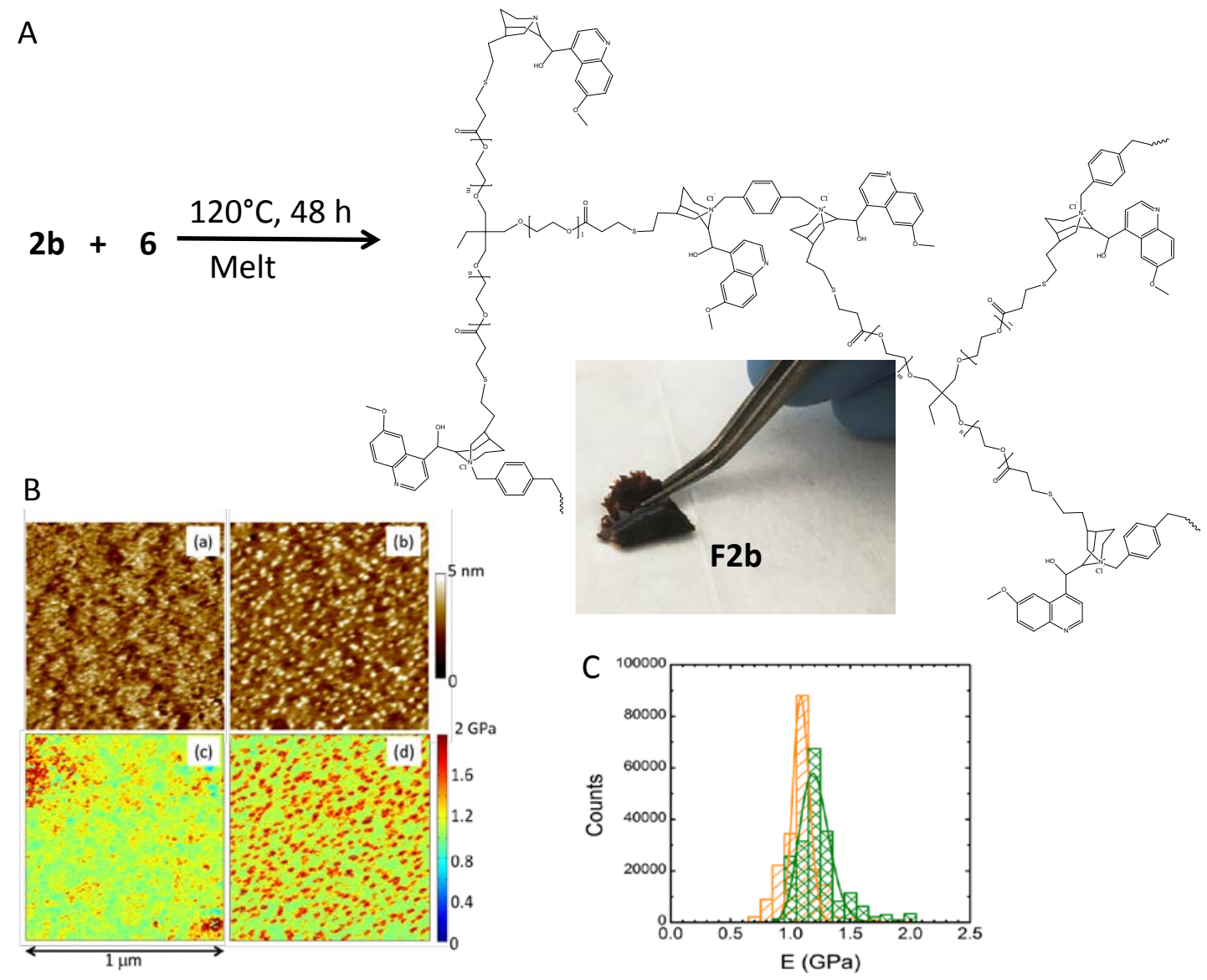

Fig. 5 A) Synthesis of quinine-based film F2b by reaction of $\mathbf{2 b}(X=\mathrm{Cl})$ and $\mathbf{6}$ via melt quaternization at $120^{\circ} \mathrm{C}$. B) Topography and Young's modulus pictures of $\mathbf{6}((\mathrm{a})$ and (c), respectively) and film F2b prepared at [2b] / [quinine] = 1/2 denoted as film $\mathbf{D}((\mathbf{b})$ and (d), respectively) as determined by PF-QNM experiments. C) Young's modulus distribution corresponding to 6 (orange) and film $\mathbf{D}$ (green).

towards quinine-based cross-linked coatings is that active films are directly obtained, as illustrated in Figure 6A. We observed fluorescence upon immersion of film $\mathbf{D}$ in water, which we attribute to the delivery of residual unreacted 6 having fluorescent quinine moieties, because un-bonded $\mathbf{2} \mathbf{b}$ that should be also released is a non-fluorescent compound. ${ }^{20}$ Similarly, if a drop of water is deposited on neat film $\mathbf{D}$, it was found to turn fluorescent very quickly (see ESI). UV-vis spectroscopy measurements revealed an absorption band located at $330 \mathrm{~nm}$, arising from quinine moieties of $6 .{ }^{21}$ Figure 6A shows the fluorescence intensity after immersion of film $\mathbf{D}$ in water, after $2 \mathrm{~h}$ with the film still remaining at the bottom of the vial, and after $24 \mathrm{~h}$ of immersion with final removal of film D from water. Figure 6B shows experimental delivery curves corresponding to two consecutive immersion cycles of $24 \mathrm{~h}$ for films $\mathbf{A}$ and $\mathbf{D}$. The delivery process was almost complete after $24 \mathrm{~h}$ and a fast delivery was observed in the first two hours for both films. As expected, at a given time the fluorescence intensity increases upon decreasing the [2b] / [quinine] ratio (i.e., upon decreasing the cross-linking degree).

Cell and bacterial tests were carried out to determine the bioactivity of the elution media from the active melt quaternized quinine-based films (see Figure $6 C$ and ESI). Remarkably, when the elution media from films $\mathbf{A}$ and $\mathbf{D}$ were incubated at $37 \stackrel{\circ}{\circ}$ for $72 \mathrm{~h}$ with mouse macrophage cell line Raw 264.7 and human dermal fibroblast (hDF) cells, cell viability above $80 \%$ was observed in both cases indicating the non-cytotoxic activity of both films. On the other hand, the elution media from films $\mathbf{A}$ and $\mathbf{D}$ were found to exhibit antibacterial properties against $E$. coli when incubated at $37^{\circ} \mathrm{C}$ for $4 \mathrm{~h}$ as illustrated in Figure 6C. Films $\mathbf{A}$ and $\mathbf{D}$ reduced the bacterial viability below 20 and $50 \%$, respectively, which can be explained by the fact that the lowest cross-linked film 
A

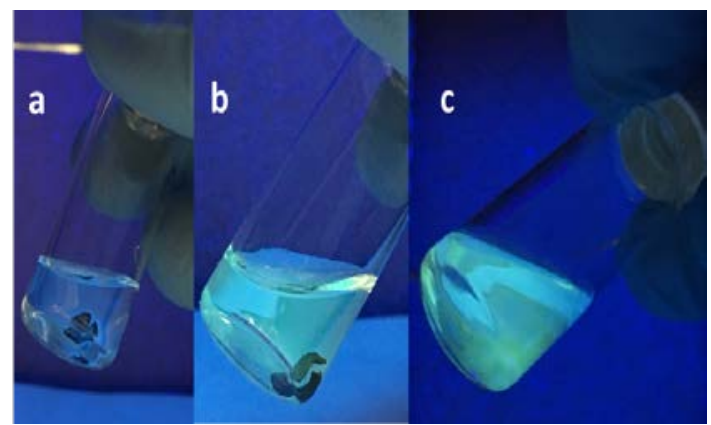

B

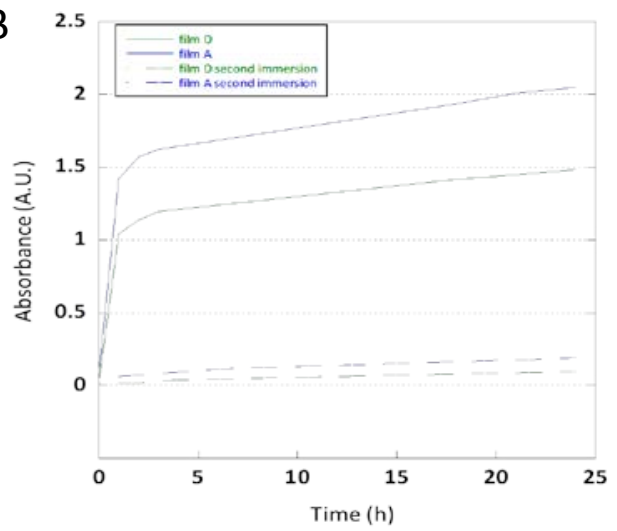

C

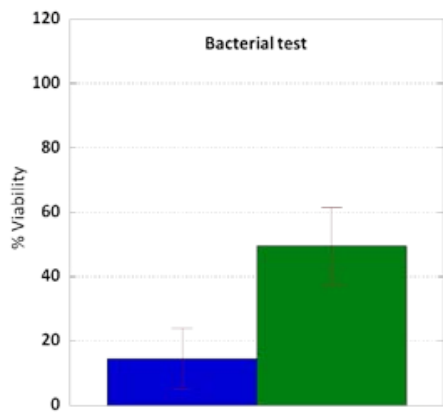

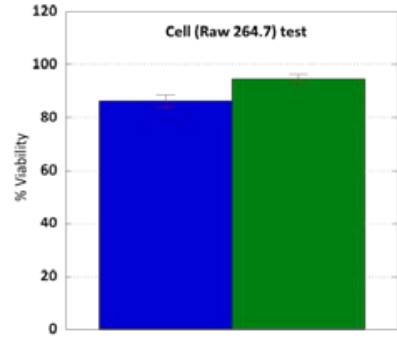

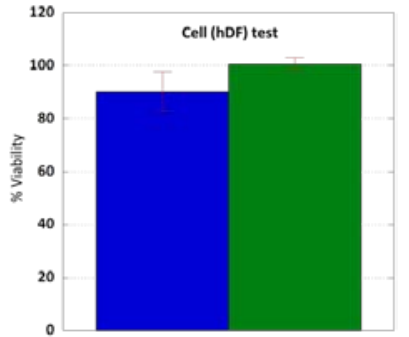

Fig. 6 A) Fluorescence observed upon immersion of film $\mathbf{D}$ in water: (a) $t=0 \mathrm{~h}$; (b) $t=2 \mathrm{~h}$; and (c) $t=24 \mathrm{~h}$ (film removed). B) Delivery curves of residual unreacted 6 from films $\mathbf{A}$ (blue) and $\mathbf{D}$ (green) corresponding to two consecutive immersion cycles of $24 \mathrm{~h}$. C) Results of bacterial (E. coli) and cell (Raw 264.7 and hDF) tests performed to the elution media of films $\mathbf{A}$ (blue) and $\mathbf{D}$ (green) (see text for details).

delivers a higher amount of active compound when compared to the highest cross-linked one. These results are of great interest for the potential development of new active bio-based products based on cinchona alkaloids. According to the results shown in Figure 6B, one cannot expect significant antibacterial activity after two immersion cycles of $24 \mathrm{~h}$ due to complete elution of the active compounds.

\section{Conclusions}

We have introduced an innovative synthetic strategy toward active nanostructured cinchona alkaloid-based coatings by means of simple melt quaternization / spreading procedures at relatively low temperature $\left(120^{\circ} \mathrm{C}\right)$ without the involvement of any solvent. Through this ground-breaking concept, we have produced active, flexible and nanostructured quinine-based films $\left(T_{\mathrm{g}}=-14^{\circ} \mathrm{C}\right.$, Young's modulus $\left.=1.3 \mathrm{GPa}\right)$. These films are able to release antimicrobial compounds against $E$. coli that are noncytotoxic against mouse macrophage and human dermal fibroblast cells. Remarkably, these kind of active cinchona alkaloid-based coatings are facile to prepare, making this strategy one of the most facile reported procedures to date to produce active bio-based films with potential use in the food-packaging, health and medical fields.

\section{Conflicts of interest}

There are no conflicts to declare.

\section{Acknowledgements}

Financial support by the Spanish Ministry "Ministerio de Economia y Competitividad", MAT2015-63704-P (MINECO / FEDER, UE) and the Basque Government, IT-654-13, is acknowledged. A. L.-S. is grateful to the University of the Basque Country for his UPV/EHU pre-doctoral grant, and to both MPC and Gipuzkoako Foru Aldundia for financial support during his stay at KTH. We thank José I. Miranda, Antonio Veloso and Daniel E. Martínez-Tong for excellent technical assistance.

\section{Notes and references}

1 R. M. Donlan, Emerging Infect. Dis., 2001, 7, 277-281.

2 P. L. Tran, N. Lowry, T. Campbell, T. W. Reid, D. R. Webster, E. Tobin, A. Aslani, T. Mosley, J. Dertien, J. A. ColmerHamood and A. N. Hamood, Antimicrob. Agents Chemother., 2012, 56, 972-978.

3 V. K. Vendra, L. Wu and S. Krishnan in Nanomaterials for the Life Sciences Vol. 5: Nanostructured Thin Films and Surfaces. (Ed.: C. S. S. R. Kumar), Wiley-VCH, Weinheim, 2010, Chap. 1, pp. 1-39.

4 S. Jepsen, T. Berglundh, R. Genco, A. M. Aass, K. Demirel, J. Derks, E. Figuero, J. L. Giovannoli, M. Goldstein, F. Lambert, A. Ortiz-Vigon, I. Polyzois, G. E. Salvi, F. Schwarz, G. Serino, C. Tomasi and N. U. Zitzmann, J. Clin. Periodontol., 2015, 42, S152-S157.

5 K. Chaloupka, Y. Malam and A. M. Seifalian, Trends Biotechnol., 2010, 28, 580-588.

6 Y. Chang, S.-C. Liao, A. Higuchi, R.-C. Ruaan, C.-W. Chu and W.-Y. Chen, Langmuir, 2008, 24, 5453-5458.

7 (a) A. d. I. S. Pereira, S. Sheikh, C. Blaszykowski, O. PopGeorgievski, K. Fedorov, M. Thompson and C. RodriguezEmmenegger, Biomacromolecules, 2016, 17, 1179-1185; (b) G. Subbiahdoss, B. Pidhatika, G. Coullerez, M. Charnley, R. Kuijer, H. C. van der Mei, M. Textor and H. J. Busscher, Eur. Cells Mater., 2010, 19, 205-213.

8 Z. Li, D. Lee, X. Sheng, R. E. Cohen and M. F. Rubner, Langmuir, 2006, 22, 9820-9823. 
9 T. S. Kaufman and E. A. Rúveda, Angew. Chem. Int. Ed., 2005, 44, 854-885.

10 D. A. Casteel in Burger's Medicinal Chemistry and Drug Discovery, $5^{\text {th }}$ Ed., Vol. 5 (Ed.: M. E. Wolff), Wiley, New York, 1997, Chap. 59, p. 16.

11 R. Wolf, A. Baroni, R. Greco, F. Corrado, E. Ruocco, M. A. Tufano and V. Ruocco, Dermatol. Online J., 2003, 9, 3.

12 S. A. Kharal, Q. Hussain, and A. S. Fakhuruddin, J. Pak. Med. Assoc., 2009, 59, 208-212.

13 R. Wolf, M. A. Tufano, V. Ruocco, E. Grimaldi, E. Ruocco, G. Donnarumma and A. Baroni, Int. J. Dermatol., 2006, 45, 661663.

14 J. Lv, Y. Qian, T. Liu and Y. Wang, Bioorg. Med. Chem. Lett., 2007, 17, 4102-4106.

15 Frontiers in Biomaterials, Vol. 3, Chitosan Based Materials and its Applications. (Eds.: G. L. Dotto, S. P. Campana-Filho and L. A. de Almeida Pinto), Bentham Science Publishers, Sharjah, 2017, pp. 249-271.

16 (a) M. B. Smith and J. March, March's Advanced Organic Chemistry: Reactions, Mechanisms and Structure. $6^{\text {th }}$ Edition. John Wiley \& Sons, Inc., New Jersey, 2007, Chapter 10, p. 555; (b) R. Lambert, A.-L. Wirotius and D. Taton, ACS Macro Lett., 2017, 6, 489-494.

17 (a) A. B. Lowe, Polym. Chem., 2010, 1, 17-36; (b) M. Claudino, M. Jonsson and M. Johansson, RSC Adv., 2014, 4, 10317-10329; (c) I. Perez-Baena, I. Asenjo-Sanz, A. Arbe, A. J. Moreno, F. Lo Verso, J. Colmenero and J. A. Pomposo, Macromolecules, 2014, 47, 8270-8280.

18 (a) J. C. Middleton and A. J. Tipton, Biomaterials, 2000, 21 2335-2346; (b) A. Södergård and M. Stolt, Prog. Polym. Sci., 2002, 27, 1123-1163.

19 (a) M. E. Dokukin and I. Sokolov, Langmuir, 2012, 28, 1606016071; (b) I. L. Ivanovska, P. J. de Pablo, B. Ibarra, G. Sgalari, F. C. MacKintosh, J. L. Carrascosa, C. F. Schmidt and G. J L. Wuite, Proc. Natl. Acad. Sci. U.S.A., 2004, 101, 7600-7605. (c) Polymer Data Handbook (Ed.: J. E. Mark), $2^{\text {nd }}$ Edition. University Press, New York, 2009, pp. 1014-1017, and pp. 1184-1187.

20 All our attempts to determine the molar ratio of $\mathbf{6}$ to $\mathbf{2 b}$ by NMR spectroscopy failed.

21 (a) R. L. O'Brien, J. G. Olenick and F. E. Hahn, Proc. Natl. Acad. Sci. U.S.A., 1966, 55, 1511-1517; (b) R. I. Allen, K. J. Box, J. E. A. Comer, C. Peake and K. Y. Tam, J. Pharm. Biomed. Anal., 1998, 17, 699-712. 